\title{
COMPRENSIÓN Y AUTOCOMPRENSIÓN EN LA HERMENÉUTICA DE GADAMER, Y ALGUNAS PERSPECTIVAS PARA EL HUMANISMO
}

\author{
María del Mar Esguerra LozadA* \\ doi:10.11144/Javeriana.uph31-63.cahg
}

\begin{abstract}
RESUMEN
En el trayectoria del 'giro espacial' de la filosofía, la hermenéutica es pensada generalmente como un método más en la filosofía, que pretende aunar esfuerzos para resolver los problemas históricos en la determinación de la verdad. Las consideraciones alrededor del método toman su importancia para las ciencias humanas en el siglo XIX con los estudios de Schleiermacher y Dilthey, pero son retomadas por Gadamer dentro de los análisis ontológicos de la comprensión, abriendo el camino para la reflexión de una hermenéutica que ineludiblemente pone en juego las consecuencias éticas de los análisis planteados, lo que puede ser omitido al centrarse solamente en el método y no en la praxis de este ejercicio comprensivo. Esto último puede detallarse en el análisis de la estructura de la comprensión y autocomprensión de la hermenéutica de Gadamer y observar a su vez las implicaciones del mismo en el estudio de las ciencias humanas y el humanismo.
\end{abstract}

Palabras clave: hermenéutica; Hans-Georg Gadamer; comprensión; autocomprensión; humanismo

\footnotetext{
${ }^{*}$ Pontificia Universidad Javeriana, Cali, Colombia.

ReCIBIDO: 25.04.14 ACEPTADO: 20.06.14

DisPonIBLE EN LÍNEA: 02.12.14

Para citar este artículo: EsGUerRa LozAdA, M.M. (2014). Comprensión y autocomprensión en la hermenéutica de Gadamer, y algunas perspectivas para el humanismo. Universitas Philosophica, 31(63), pp. 97-117, ISSN 0120-5323, ISSN en línea 2346-2426, doi: 10.11144/Javeriana.uph31-63.cahg
} 


\title{
COMPREHENSION AND SELF- UNDERSTANDING IN GADAMER'S HERMENEUTICS, AND SOME PROSPECTS FOR HUMANISM
}

\author{
María del Mar Esguerra LozadA
}

\begin{abstract}
Hermeneutics is generally thought as a method in philosophy, which aims to unify efforts in order to resolve historical issues in determining the truth. Considerations about method gain importance to the human sciences in the nineteenth century with studies by Schleiermacher and Dilthey, but they are taken up by Gadamer within the ontological analysis of understanding, paving the way for the reflection of a hermeneutics that inevitably puts into play the ethical implications from discussions, which can be omitted to focus only on method and not in the praxis of this comprehensive exercise. The latter can be detailed in the analysis of the structure of self-understanding and comprehension in Gadamer's hermeneutics and observe in turn the implications of this analysis in the study of human sciences and humanism.
\end{abstract}

Key words: hermeneutics; Hans-Georg Gadamer; comprehension; self-understanding; human existence 
LA HERMENÉUTICA HA SIDO TOMADA DESDE SU INICIO como un instrumento de las ciencias humanas. La introducción del concepto de comprensión por parte de Wilhem Dilthey tuvo como objetivo separar el conocimiento obtenido por parte de las ciencias sociales, de aquel que nos proporcionan las ciencias naturales bajo el concepto de explicación. Fue la comprensión la que se constituyó como clave en el acceso al conocimiento sobre lo humano. De esta forma, se piensa la hermenéutica como el método característico de las ciencias humanas que, a diferencia del científico, estudia la particularidad del sentido de las acciones humanas. Siendo así, la comprensión se convierte en el fundamento que permitirá que las "ciencias del espíritu", como bien las llamaba Dilthey, constituyan un conocimiento propio que sustraiga los fenómenos propiamente humanos de la explicación bajo leyes universales.

Pero hay una posición diferente respecto al conocimiento de las ciencias humanas que la hermenéutica gadameriana realiza frente a este primer paso de ubicar la comprensión (verstehen) como contrapartida de la explicación (erklëren $)^{1}$. Se trata de la caracterización que este filósofo establece de la noción de comprensión frente a la instaurada por Dilthey, puesto que para Gadamer la comprensión no solo se circunscribe a un método que intenta dar cuenta de los procesos y acciones propiamente humanas ${ }^{2}$. En este sentido, la comprensión rebasa ese marco metodológico y se constituye como la forma en la que tiene expresión la existencia misma. La comprensión no es una instancia a la que se recurre para entender unos procesos y acciones particulares de los hombres, como si tuviéramos la posibilidad de hacer uso o no de ella; esta hace parte de la existencia misma en su despliegue para relacionarse con el mundo. En términos heideggerianos, la comprensión sería un existenciario fundamental que posibilita otras formas de conocimiento más elaboradas.

"Nuestro vivir es un vivir en diálogo", afirmó Gadamer. De esta manera, al dar cuenta de la comprensión, es ineludible remitirnos al espacio en donde

\footnotetext{
${ }^{1}$ Esta dualidad es propia de la discusión de la hermenéutica en el Romanticismo. Para una mirada de la dialéctica que se entabla entre comprensión y explicación véase: Ricœur, 1995, pp. 83-100.

2 Bien lo expresa Grondin (2008, p. 72) al afirmar que "la idea de Gadamer es que Dilthey sucumbe a una concepción de la verdad inspirada en la metodología de las ciencias exactas, que declara anatema toda implicación de la subjetividad".
} 
esta ocurre: el lenguaje. Y dado que este es el medio en el que se realiza la comprensión y en la que tiene lugar la experiencia de sentido, la experiencia hermenéutica -fundamento de la relación con el mundo- tiene carácter lingüístico. El conocimiento del mundo, de los otros y de nosotros mismos implica siempre el lenguaje, específicamente, el que tenemos. Por tanto, el lenguaje no es un instrumento que esté a la mano para ser utilizable en el proceso del conocimiento sino que, como nuestra permanencia en el mundo siempre denota comprensión, es el espacio en el que se nos da el mundo con sentido.

Gadamer intentará mostrar que el lenguaje es el lugar en donde se realiza la comprensión de los textos a la manera de una conversación, pero no solo se restringe al ámbito textual, sino que proyecta este análisis a la comprensión que pone en juego la hermenéutica en los distintos ámbitos en donde el sentido debe ser re-instaurado. En esta forma, si por comprender se entiende "[...] el ponerse de acuerdo en la cosa, no ponerse en el lugar del otro y reproducir sus vivencias" (Gadamer, 1996, p. 461), el lenguaje es medio en el que se realiza el acuerdo.

En lo que sigue, revisaremos el concepto de comprensión y autocomprensión en la hermenéutica de Gadamer para mostrar lo que significa una experiencia auténticamente hermenéutica, lo que nos dará el marco conceptual para hablar de lo que entendemos por humanismo. Un humanismo al que llamamos hermenéutico, pues implica toda la caracterización propia de esta manera de hacer filosofía.

REALICEMOS EL PRIMERO DE NUESTROS COMETIDOS: dar cuenta de la noción de comprensión. Bien sabemos que Gadamer recibe de Heidegger ese primer impulso en la determinación de la comprensión como una experiencia ontológica que realiza el hombre en la medida en que interpreta el mundo circundante. Gadamer encuentra en Heidegger, de un lado, cómo se puede comprender el ser; de otro, cómo el comprender es ser. La comprensión es, entonces, no solo el resultado de la actividad de la conciencia comprensora, sino también el modo como acontece el ser mismo. En términos generales, la comprensión adquiere un estatus ontológico, y por esto mismo el análisis de la puesta en praxis de esta noción nos permitirá adentrarnos en los ejes determinantes de la existencia humana. De esta manera, entender 
la comprensión dentro de una experiencia auténticamente hermenéutica nos llevará a afrontar las determinaciones propias del ser humano como características ontológicas, tomadas siempre desde una perspectiva existenciaria, es decir, móviles y dinámicas, pues se fundamentan en la existencia misma.

Iniciamos este estudio sobre la comprensión desde lo que en Heidegger se llama el "círculo de la comprensión". Si bien dicha estructura circular adquiere con el análisis existencial de Heidegger su verdadero significado, Gadamer nos aproxima a lo que realmente quiere dar a entender con esta noción por medio de la comprensión textual. Es en esta instancia cuando abordamos lo que significa la circularidad, pues la proyección del sentido se hace siempre desde la interpretación de los conceptos previos. Por eso Gadamer (2007, p. 333) sostiene que "elaborar los proyectos correctos y adecuados a las cosas, que como proyectos son anticipaciones que deben confirmarse «en las cosas», tal es la tarea constante de la comprensión. Aquí no hay otra objetividad que la convalidación que obtienen las opiniones previas a lo largo de su elaboración".

El círculo de la comprensión entendido por Gadamer (2007, p. 334) como la anticipación de sentido está marcado por la inevitable presencia de prejuicios y opiniones previas, entendidas como hábitos lingüísticos y opiniones de contenido que constituyen la pre-comprensión de los textos y determinan la comprensión misma. La tarea hermenéutica debe hacer presencia en este juego de prejuicios desde las partes hablantes, ya que por el carácter esencialmente prejuicioso el problema hermenéutico adquiere toda su validez. El sentido del texto es una permanente tarea que debe exigir el esfuerzo por centrarse en la cosas mismas; la tensión entre los prejuicios debe dejar espacio para escuchar lo que el texto dice, ya que no se trata de entregarse a los prejuicios como algo inevitable de la comprensión, sino de ponerlos a la vista para saber de qué manera van a poder entrar en diálogo con lo que el texto nos habla. Por esta razón Gadamer (2007, p. 335) afirma que:

Una conciencia formada hermenéuticamente tiene que mostrarse receptiva desde el principio para la alteridad del texto. Pero esta receptividad no presupone ni «neutralidad» frente a las cosas ni tampoco auto cancelación, sino que incluye una matizada in-corporación de las propias opiniones previas y prejuicios. 
No se trata de caer en el prejuicio ilustrado de evitar todo prejuicio, condición imposible de realizar según Gadamer, ni tampoco dejarse influenciar enteramente por los prejuicios imperantes. La capacidad hermenéutica, esfuerzo que no acontece espontáneamente, requiere de la voluntad de los interlocutores para hallar la cosa en común de la que se está hablando, lo que implica saber abandonar aquellos prejuicios que al ponerse en contraste con la verdad objetiva del texto no encuentran su validez. Esto requiere de una conciencia metódica que controla sus anticipaciones desde su reconocimiento para dejar decir al otro o al texto su opinión y ponerlas en relación con las propias. Como vemos, lo que Gadamer expone en este proceso de dejar hablar al otro para encontrar el consenso en la comprensión, es lo que denomina justamente como la conversación que se entabla en el ejercicio de la comprensión. Para el filósofo alemán la conversación es el modo como accedemos a la comprensión del texto o de la tradición, que se da con el ejercicio de preguntar cuando nos reconocemos interpelados por el otro.

Al respecto, para no levantar críticas sin fundamento a la hermenéutica gadameriana, hay que tener claro que, si la comprensión es un modo en el que acontece el ser, eso no implica que toda situación que requiere de una tarea hermenéutica vaya a resolverse por el simple hecho de que la comprensión es algo que se nos da cuando interpretamos alguna cosa. Si Gadamer hace referencia a que la comprensión es una experiencia que se realiza cuando entramos a leer el mundo, también es bastante preciso al indicar que la puesta en marcha de una labor hermenéutica -que tiene lugar cuando el sentido no alcanza a hacerse comprensivo, o cuando no se da la univocidad, pues bien, "el problema hermenéutico es un problema del correcto acuerdo sobre un asunto" (Gadamer, 1998, p. 237)- exige rupturas y consensos que deben emprenderse desde la voluntad de los participantes en una instancia de conciencia y método, y así dar cuenta de la relación entre la anticipación de sentido y el sentido del otro (llámese texto, tradición o individuo). Por eso el filósofo dirá muy agudamente que:

No se trata de una comprensión universal ingenua en la que se armonice el mundo a través del diálogo, la verdadera hermenéutica, debe movilizar la (...) crítica y la impugnación de lo anquilosado o lo enajenado como el reconocimiento o la defensa del orden establecido (...) el lenguaje desarrolla siempre una tensa vida en el antagonismo entre convencionalidad y ruptura revolucionaria. (Gadamer, 1998, p. 335) 
Según lo dicho, la comprensión requiere de la voluntad para encontrar el acuerdo en un problema hermenéutico claramente expreso. Pero también es preciso saber que la comprensión acontece espontáneamente cuando, sin tener que esperar la voluntad para ejercitar la interpretación comprensiva de nuestra lectura de lo que nos circunda, nos introducimos en el mundo. Vemos bien, entonces, que debemos atender a estos momentos de la comprensión para enmarcar correctamente los éxitos y fracasos del diálogo hermenéutico, que también nos servirán para entablar los requerimientos en el conocimiento de las ciencias humanas.

Ahora, se hace necesario especificar la comprensión desde el interior de la conversación para poder llevar a cabo la tarea hermenéutica. ¿Qué se busca en una conversación con un texto, con la tradición o con el otro? La respuesta para Gadamer es directa y concreta: ponerse de acuerdo en lo que se está hablando y dar con la comprensión de la cosa en cuestión. Por ello sostiene el filósofo que:

(...) comprensión significa entenderse en la cosa, y sólo secundariamente destacar y comprender la opinión del otro como tal. Por eso la primera de todas las condiciones hermenéuticas es la pre-comprensión que surge del tener que ver con el mismo asunto. Desde esto se determina lo que puede ser considerado como sentido unitario (...). (Gadamer, 1998, p. 130)

Hay que aclarar que si bien Gadamer menciona la llegada a un sentido unitario en la búsqueda de la comprensión, no hay que suponer que esto elimina los posibles otros sentidos que puedan surgir en otras interpretaciones generadas en circunstancias hermenéuticas diferentes; esta pluralidad es lo que precisamente debemos resaltar de este ejercicio. No se llega a un sentido, como al final de un camino recorrido, como el punto concluyente de un texto, sino que se crea permanentemente un sentido a partir de uno ya dado. Se trata de una tarea inagotable debido al diálogo permanente con la tradición, el cual, a la manera de círculos concéntricos, se ensancha cada vez que nos dejamos interpelar por lo otro. Este movimiento permanente se presenta en la comprensión por el hecho de estar determinada por la tradición. Gadamer (2007, p. 368) lo menciona del siguiente modo: “(...) el verdadero sentido contenido en un texto o en una obra de arte no se agota al llegar a un determinado punto final, sino que es un proceso infinito". Por el hecho de hablar de univocidad no se quiere dar a entender un sentido único irrevocable sino que, por la condición de que la comprensión acontece en el tiempo, se manifiestan procesos infinitos de ella dentro de una misma cosa 
cuestionada. En definitiva, es la distancia la que permite el movimiento en la comprensión, lo cual sucede con los textos, la tradición y las conversaciones:

Cuando intentamos entender un texto no nos desplazamos hasta la constitución psíquica del autor, sino que, ya que hablamos de desplazarse, lo hacemos hacia la perspectiva bajo la cual el otro ha ganado su propia opinión. Y esto no quiere decir sino que intentamos que se haga valer el derecho de lo que el otro dice. Cuando intentamos comprenderle hacemos incluso lo posible por reforzar sus propios argumentos. Así ocurre también en la conversación...Es tarea de la hermenéutica explicar este milagro de la comprensión, que no es una comunión misteriosa de las almas sino participación en un sentido comunitario. (Gadamer, 2007, p. 361)

La tradición se realiza a través de la fusión de prejuicios "fundamentales y sustentadores", y su permanencia es la que permite el constante movimiento de la comprensión y su perenne vitalidad en la historia; por tanto, "el que quiere comprender está vinculado al asunto que se expresa en la tradición, y que tiene o logra una determinada conexión con la tradición desde la que habla lo trasmitido" (Gadamer, 2007, p. 365). La comprensión que expresamos en una conversación, en una interpretación de un texto o de alguna cosa, está inscrita siempre en una tradición, en un pasado, en un sentido de mundo que determina nuestro modo de hablar. Esta inscripción se mueve en una tensión entre familiaridad y extrañeza, tensión que marca la tarea hermenéutica y directamente el diálogo. La conversación, los esfuerzos por ponerse de acuerdo en lo que se habla y se comprende, y la comprensión dentro de los procesos interpretativos de comprensión del mundo, se mantienen siempre en diversas tensiones ontológicas que determinan su curso. Una de ellas es la tradición. Otra, ligada estrechamente a la anterior, es la de autoridad. En la conversación cada interlocutor debe disponerse dentro del reconocimiento de una opinión ajena más acertada. Dicho reconocimiento no se produce por imposición sino por la razón misma que es capaz de determinar que el otro sabe más; es un acto de libertad que concede autoridad. El reconocimiento de que la tradición todavía nos dice algo y determina ampliamente lo que pensamos, se enfrenta a la extrañeza del sentido que ya no se aplica actualmente y no responde a nuestras inquietudes, pues la obediencia a la autoridad no es el acallamiento de la razón sino, por el contrario, es el cuestionamiento el que muestra la tensión entre el reconocimiento de una verdad trasmitida operante y aquella que debe ser objeto de crítica y de re-significación. Por esta razón, la tradición no debe ser pensada al modo de un objeto que se conserva y persiste y al cual se pueda recurrir cada vez que se necesite tener una mirada 
histórica. La experiencia hermenéutica, fundamentada en el círculo de la comprensión, es experiencia de la tradición como un diálogo en segunda persona, elcual explica la manera de relacionarnos con ella. Es precisamente este diálogo el que permite que la tradición sea algo vivo que nos habla y tradición de la que no podemos separarnos en un análisis del modo sujetoobjeto. Siendo esto así, la conciencia hermenéutica es una conciencia que se sabe limitada por los prejuicios, por su propia historia y comprensión generada en medio de esta relación. La tradición no es algo pasivo que, por ser autoridad, se recibe arbitrariamente; es más, no se recibe en cuanto tal. Como dirá Gadamer:

Nos encontramos siempre en tradiciones, y este nuestro estar dentro de ellas no es un comportamiento objetivador que pensara como extraño o ajeno lo que dice la tradición; esta es siempre más bien algo propio, ejemplar o aborrecible, es un reconocerse en el que para nuestro juicio histórico posterior no se aprecia apenas conocimiento, sino un imperceptible ir transformándose al paso de la misma tradición. (2007, p. 351)

Por tanto, nuestra relación con el pasado debe ser un eje fundamental para el procedimiento investigativo de las ciencias humanas. Lo que intenta mostrar Gadamer al fundamentar la filosofía hermenéutica, a diferencia de sus predecesores, es que al "integrar la comprensión al suelo de la praxis de la vida misma, las ciencias humanas resultan también profundamente arraigadas en la existencia" (Gama, 2009, p. 127). Aunque en la hermenéutica gadameriana no se reemplaza la epistemología por una ontología del acaecer de la comprensión en la existencia, sino que se vuelve esta última el punto clave para decidir sobre el sentido de los productos de las acciones humanas, sí se delimita la comprensión en su análisis, como venimos haciendo, y se fijan las directrices para el conocimiento de las características más propias del ser humano en la existencia.

La relación comprensión-tradición, en la que se denota una tensión ontológica, nos dará paso a observar otro condicionamiento propio de la comprensión, al que se dará tratamiento bajo la caracterización de la opinión válida del otro.

Lo importante de este momento en el que se hace ostensivo un cuadro ontológico -tensiones-, en el que se genera el ejercicio de la comprensión hermenéutica, es la manera como este demarca los rasgos fundamentales en que la existencia del hombre se expresa en el mundo. El análisis del 
fenómeno de la comprensión proporciona la apertura al entendimiento de la finitud e historicidad del ser humano y, al mismo tiempo, de los elementos constitutivos de su ser. La ejecución de una verdadera comprensión no es simplemente un recurso metodológico en el conocimiento, aunque sí debe tenerse en cuenta al momento de adentrarse en los alcances que se plantean las ciencias humanas, al igual que un momento auto-reflexivo en el que se pone frente a cada humano su papel en el mundo, su historia, sus sentidos y su manera de expresarlo y de ser expresado por otros. Esta reflexión no es a la manera de una conciencia emancipadora de todo condicionamiento que busca objetivar el conocimiento sino que, a través de una puesta en marcha de la filosofia hermenéutica, es una forma distinta de reflejar su ser en estos procesos cognoscitivos.

Vemos, entonces, que las condiciones en las que se da la comprensión no son puestas por el sujeto, están dadas. Ante ello, Gadamer muestra los condicionamientos propios de la comprensión que determinan el proceso de conocimiento. Por eso, en relación con la tradición, Gadamer (2007, p. 360) sostiene que:

El comprender debe pensarse menos como una acción de la subjetividad que como un desplazarse uno mismo hacia un acontecer de la tradición, en el que el pasado y el presente se hallan en continua mediación. Esto es lo que tiene que hacerse oír en la teoría hermenéutica, demasiado dominada hasta ahora por la idea de un procedimiento, de un método.

Gadamer no solamente ha querido definir el movimiento de la comprensión como una relación del todo a la parte y viceversa, método de la hermenéutica de Scheleiermacher, sino que ha visto, a través de la idea de Heidegger, el movimiento circular de la comprensión desde la anticipación de sentido que guía la comprensión. Esta anticipación de sentido es una unidad de sentido perfecta; en ella el investigador no tiene que desplazarse hacia la subjetividad del otro para entender lo que dice, sino que se desplaza hacia lo que el otro dice, lo que denota la posibilidad de que el otro exprese su propia opinión, pero no solamente en el sentido de dejarlo hablar, sino en el sentido de que se ha dado validez a lo que él dice, a sus argumentos como la opinión válida del otro. Con esto resaltamos una nueva caracterización fundamental del hombre: siempre está determinado en su relación con el mundo por el otro, que es a la vez una estructura de saber. La tarea de la hermenéutica es entablar el diálogo entre estas estructuras que permanentemente entran en discontinuidades de sentido. En un verdadero ejercicio hermenéutico la 
opinión del otro debe ser tenida como cierta y debe entrar en valoración frente a lo que se está discutiendo. Es precisamente en el ejercicio de la comprensión, enmarcado en la tradición, como el saber queda circunscrito a una situación precisa, no reclamando universalidad por fuera de los horizontes en los que se ha generado el diálogo. Es sabido que el recurso del condicionamiento histórico del conocimiento no se da desde la filosofía hermenéutica. La conciencia histórica es algo que venía siendo trabajado por sus predecesores de la escuela historicista, pero Gadamer pone el énfasis de otra manera. La idea de situar el objeto de estudio en un contexto histórico, no se hace en el desplazamiento del sujeto investigador hacia el horizonte del objeto, dejando a un lado el conocimiento que trae desde su horizonte. Lo que propone Gadamer es lo que denomina una fusión de horizontes. Estos horizontes son horizontes de mundo que se han configurado dentro de una sólida tradición: el lenguaje, en el que siempre se dirimen los problemas del sentido de la cosa en cuestión a comprender. Por tanto, no es posible no historiar la experiencia hermenéutica.

LA SECCIÓN ANTERIOR NOS ABRE EL CAMINO PARA referirnos al tema del humanismo desde una filosofía hermenéutica. Por eso, en este apartado, damos paso al análisis de la autocomprensión en la hermenéutica gadameriana y su importancia acerca del análisis de lo que llamamos humanismo hermenéutico.

Según la estructura de la comprensión, quien comprende algo no solamente comprende la cosa en cuestión, sino que, también, en este camino, se comprende a sí mismo. Es precisamente la tensión entre proyección anticipativa, la unidad de sentido totalmente desplegada, la comunión de prejuicios y aquellos a los que se enfrenta en la tarea de comprender momento conocido como fusión de horizontes a partir de una situación-, la que hace posible un crecimiento y ensanchamiento del propio horizonte de comprensión. Al permitir reconocer que la cosa a comprender queda mejor explicada y conocida cuando se involucra una parte de sentido no puesto por mí, lejano a mi comprensión, gano intelección tanto del objeto como de mí mismo, pues reconozco prejuicios propios que no permitían avanzar en la comprensión.

Al revisar la manera como se ha explicado la autocomprensión, Gadamer reconoce que este concepto no solamente se debe analizar desde 
una perspectiva psicologista (auto-conocimiento), entendido como lo ya dado, sino a la manera de la autoconciencia hegeliana que se conoce a sí misma en el otro ${ }^{3}$. Ve en la explicación teológica de este concepto y en los análisis heideggerianos la manera como se realiza una crítica a la concepción moderna epistémica en la relación sujeto-objeto. Todo comprender pone en juego siempre una dimensión reflexiva, pero no a la manera de una conciencia que pueda objetivarse y se pueda tomar a distancia para su conocimiento, pues esto implica una estancia de reflexión enteramente subjetiva en la que el otro ha quedado anulado, ya sea como trascendencia o inmanencia de mi conciencia. La idea de Gadamer es otra. Cuando introduce como fundamento de la comprensión la pertenencia a la tradición, está configurando el carácter histórico de esta ${ }^{4}$, con lo cual refuerza la idea de que toda comprensión es auto-comprensión. Entendamos mejor. En la comprensión de la tradición se nos muestran los prejuicios que determinan nuestro sentido de mundo; esto significa comprender las posibilidades de mi propia comprensión, que no es otra cosa que la comprensión de mi propia existencia. La propuesta de Gadamer involucra en gran parte lo desarrollado por Heidegger en su analítica existencial, en cuanto que cada comprensión es comprensión de ser, del Da-sein que es un ser que se comprende y que comprende, a la vez, sus propias posibilidades de comprensión (Grondin, 2002, pp. 38-39). Dado que estos análisis que se desprenden de Heidegger no conllevan una hermenéutica de la existencia (como se hace en Heidegger), Gadamer, a través de la noción de comprensión, pretende sacudir de las ciencias humanas la idea epistemológica que prevalece en la tradición de Dilthey y en la metodología de las ciencias humanas (Grondin, 2002, p. 39).

Una comprensión, por el hecho de ser histórica, revertirá en un momento auto-comprensivo que se hace patente ineludiblemente en el enfrentamiento con el otro, de tal manera que es el otro quien me constituye en mi limitación, necesaria para conocer mis propias posibilidades. Así, aunque la pretensión de Gadamer consiste en fundamentar las ciencias humanas y presentar

\footnotetext{
${ }^{3}$ También se puede ver que los análisis heideggerianos difieren de la caracterización de la conciencia de la historia como la autoconciencia en la fenomenología hegeliana. Para profundizar en la relación entre Hegel y Gadamer en lo concerniente a la conciencia, véase: Gama, 2002, pp. 41-78.

${ }^{4}$ Que desde los análisis de la historia efectual que realiza Gadamer en Verdad y Método es mejor comprendido este carácter histórico y la dinámica entre las situaciones hermenéuticas.
} 
su posición frente a sus antecesores, no solamente se queda en un ámbito epistemológico, también extiende el análisis hermenéutico a la relación del hombre con el mundo.

Una parte de la descripción que realiza Gadamer del concepto de autocomprensión lo hace en el ámbito de la estética, lo cual le permite mostrar el carácter propio de la verdad de las ciencias humanas y la praxis comprensiva de esta ciencia. Para Gadamer es claro que la experiencia estética posibilita una auto-comprensión; en el encuentro con la obra de arte que es la presencia de un mundo, se reconoce uno mismo en algo diferente "que incluye la unidad y mismidad de eso otro" (Gadamer, 2007, p. 138), y en alguna medida, como él dice, se hacen patentes los límites de "la auto-comprensión histórica de la existencia", pero no en una experiencia que nos ponga a distancia de estos, sino que es en el mismo movimiento de la auto-comprensión en el que vivimos permanentemente lo que nos limita, siendo esto la continuidad de la auto-comprensión.

Una experiencia genuinamente hermenéutica va a repercutir en una experiencia de la existencia misma del que la realiza, debido a que esta no queda intacta al efectuar conscientemente la tarea hermenéutica de ganar comprensión de la cosa que debe ser comprendida. Pero esto no se genera de manera gratuita, como bien vimos, si todos los procesos de comprensión se realizan en diálogo con otros y si la tarea de la hermenéutica, desplazarse hacia la cosa misma, introduce la opinión del otro como válida dentro de esta conversación; es innegable que hay un presupuesto que debe siempre estar operando para tener éxito en esta labor. El postulado obligatorio que debe estar presente para reconstruir el sentido propio de la cosa en diálogo es la aceptación del otro, escucharlo, admitir su validez en la construcción de sentido y tener voluntad ${ }^{5}$ de abandonar algunas de mis consideraciones conceptuales.

Por tanto, podemos detectar una cierta auto-comprensión que permanentemente está en juego de forma inconsciente en el momento en que no podemos hallar todos los efectos del estar en la tradición, en la historia, (limitaciones naturales del mismo estar en tradición); sin embargo, el trabajo que corresponde a cada hombre para que su existencia sea auténtica, consiste

\footnotetext{
${ }^{5}$ Momento que diferenciábamos anteriormente en la experiencia hermenéutica.
} 
en llegar a reconocer la manera como se halla constituido el mundo y las relaciones de comprensión que se tejen con los otros. Se trata, en últimas, de reconocer siempre el desarrollo de mis posibilidades y la manera en que un mismo asunto u objeto ostenta sentidos que han sido configurados a partir de situaciones hermenéuticas concretas que entrañan mundo, historia y verdad.

Ahora bien, si pensamos el humanismo como "meditar y cuidarse de que el hombre sea humano en lugar de no humano" (Heidegger, 2000, p. 264), entonces un verdadero ejercicio hermenéutico entendido como la praxis de una experiencia auténticamente hermenéutica, nos direcciona a lo más propio y verdadero de cada hombre: su humanidad, aquello que lo hace ser lo que es. Tomamos esta definición de Heidegger, que contiene su propia estructura analítica hacia la concreción, para ser configurada desde la hermenéutica de Gadamer. Este nuevo giro nos obliga a construir ahora el lazo entre humanismo y praxis hermenéutica.

El ejercicio hermenéutico en relación con el otro, ya sean textos o sujetos, nos enfrenta a nuestra propia humanidad, a nuestra esencia, como dirá Heidegger. Dicha humanidad la podemos configurar desde Gadamer como una auténtica comprensión que se realiza en una verdadera experiencia. La esencia de lo que somos, según una filosofía hermenéutica, se entenderá como ese ser propio que se nos revela en la experiencia que hacemos con el lenguaje en el ejercicio comprensivo con los otros. Entonces, pensar lo humano dentro de la hermenéutica es una referencia al conocimiento que podemos decantar sobre los límites de nuestra propia existencia a través de la experiencia del otro, ínsita en cada ejercicio comprensivo. Las situaciones comprensivas que una praxis filosófica fundamentada en la hermenéutica se basan en el auto-conocimiento que a partir del otro cada uno puede realizar. Así, para Gadamer, un verdadero hombre es el que siempre puede realizar una experiencia alrededor de algo, precisamente porque siempre habrá manera de continuar con la construcción del sentido. Cada experiencia hermenéutica hace patente, entonces, en una confrontación de mis propios horizontes de sentido, los otros que están en juego y reconoce la situación temporal en la que acaece cada comprensión. Esto inevitablemente muestra la dificultad de reconocer su propio saber, de identificar los efectos de la tradición y de discernir cuáles son los prejuicios que movilizan su visión de mundo.

Es así como en el ejercicio de la comprensión mediante el diálogo con los otros se puede trazar una humanitas del hombre, entendida como lo más 
propio del ser humano. Una experiencia auténticamente hermenéutica nos pone de presente los marcos fundamentales en los que se dirime nuestra existencia humana. Estas limitaciones (que no deben ser pensadas como algo negativo) o marcos fundamentales de la existencia humana, siguiendo los análisis de los conceptos de comprensión y autocomprensión propuestos por la filosofía de Gadamer, son identificados como aquellas tensiones ontológicas en las que se mueve la comprensión, base de toda experiencia hermenéutica. Por lo tanto, si aceptamos que nuestra comprensión ineludiblemente se expresa entre la familiaridad y extrañeza de sentido, es decir, entre el pasado que nos condiciona la significatividad de las palabras y un sentido que se proyecta dentro de una nueva construcción significativa que pretende llenar el vacío de sentido que el lenguaje no alcanza a expresar; además, si podemos aceptar que la constitución de nuestra memoria se debate entre el olvido y el recuerdo de aquellos sentidos que en cada época van moviéndose y dejan solamente una estela de duda en las cosas y fenómenos que aparecen como nuevos viejos conocidos, los cuales nos inquieren dentro de nuestro lenguaje actual para reclamar su comprensión adecuada y, también, si reconocemos que nuestra comprensión está imbuida de prejuicios que condicionarán cada praxis vital que requiere de una comprensión de mundo; entonces, toda praxis filosófica mostrará inevitablemente que los sentidos que se ponen en juego en el momento de construir la comprensión de algo se enfrentan no solo a verdades que pueden ser dirimidas en el plano de una racionalidad argumentativa sino que, al estar determinados por tradiciones, estas siempre tendrán que vérselas con perspectivas, con horizontes de mundo, con verdades otras y no solo con creencias; en últimas, con la vida misma. Por tanto, se hace imperiosa la siguiente tarea, propia de las ciencias humanas y que ha de ser asumida seriamente por ellas: repensar el método, la forma y la didáctica para crear consensos y capacidades de juicio que permitan decidir qué es lo correcto y qué no.

Esta labor consiste en hacer consciente, quizás en una exposición metódica, la manera como se mueve esta comprensión humana, con el fin de salvaguardar la humanidad del hombre. Como las ciencias humanas tienen a su cargo un conocimiento y una verdad que no se alcanza a través del método diseñado por las ciencias naturales, tendrá que reconfigurar y reconceptualizar lo que se entiende por verdad, fin de todo conocimiento, lo que implica una nueva forma de saber. Por esta razón, Gadamer realiza una revisión de los principales conceptos del humanismo en Verdad y Método. La exposición de conceptos como formación, sentido común, capacidad de 
juicio y gusto, no solamente se hace para presentar una mirada histórica a la tradición humanista que tiene de base la hermenéutica en su desarrollo. Las posiciones de Gadamer frente a cada uno de estos conceptos allanan el terreno para la construcción del saber y la verdad de las ciencias del espíritu, pues es desde el humanismo como se direcciona una comprensión de la experiencia de verdad de estas ciencias. Si Gadamer intenta rescatar un tipo de conocimiento que las ciencias del espíritu ofrecen con la misma validez que las ciencias naturales, lo hace reconociendo que la verdad no es exclusivamente diseñada por medio de un conocimiento conceptual. Por ello inicia su búsqueda de una verdad a través del arte. La pregunta por la verdad de las ciencias del espíritu tendrá que ser auscultada desde la estética. Pero "si queremos mostrar la insuficiencia de esta auto interpretación de las ciencias del espíritu y abrir para ellas posibilidades más adecuadas tendremos que abrirnos camino a través de los problemas de la estética" (Gadamer, 2007, p. 74).

El recorrido que Gadamer presenta de estos conceptos básicos del humanismo le sirven, especialmente, para mostrar la caracterización única del tipo de saber que se despliega con el manejo de los problemas que tratan las ciencias del espíritu, y con esto, la manera como debe proceder esta ciencia. Hay que mirar más allá de la objetivación del método científico que ha cercenado otras miradas comprensivas, otras formas de tejer saber, como dirá Husserl al referirse a la crítica al positivismo científico. En palabras del fenomenólogo:

La exclusividad con que en la segunda mitad del siglo XIX, la total visión del mundo de los seres humanos modernos se deja determinar y cegar por las ciencias positivas y por la "prosperity" de que son deudores, significó un alejamiento indiferente de las preguntas que son decisivas para una auténtica/ ((4)) humanidad. Meras ciencias de hechos hacen meros seres humanos de hechos. (Husserl, 2008, §2, p. 50)

Hay una crítica muy generalizada a esta pretensión de cientificidad proyectada a todo saber y a toda labor que habla de conocimiento y verdad. Cuando Gadamer apela al concepto de sensus communis muestra que la referencia a este concepto romano es un camino para acercarse a una verdad que connota una caracterización distinta de la enteramente científica, esta es la misma pretensión de la retórica humanística frente a la ciencia moderna. Este concepto es una especie de sentido moral y político, el bon sens, que vincula 
mis acciones con las de los demás. Se trata de una manera de encontrar una virtud para las cuestiones prácticas de la vida, que Shaftesbury la representa como la sympathy, como la virtud social e intelectual (Gadamer, 2007, p. 55), y que para Bergson es "fuente común de pensamiento y voluntad, es un sens social que evita tanto las deficiencias del dogmático científico que busca leyes sociales como del utopista metafísico" (Gadamer, 2007, p. 56). Pero este momento de la verdad, según Gadamer, se perdió en la auto-reflexión de las ciencias humanas con la pretensión cientificista que desacredita cualquier otro conocimiento y que obliga a las ciencias del espíritu a, de una parte, adoptar el método de las ciencias naturales y, de otra, perder para la verdad otros afluentes como el sentimiento y la empatía.

En Heidegger, a través del concepto de befindlichkeit se puede ver la manera cómo, a partir de los estados anímicos, hay una apertura de mundo tan auténtica que ni la mirada contemplativa de la ciencia puede alcanzar (Heidegger, 2003, p. 162). Heidegger hace mención a la apertura del estado de ánimo porque es desde ella en donde puede reconocerse un estar-en-el-mundo. Por disposición afectiva (Befindlihckeit) se ha traducido generalmente afectividad, lo que lleva a pensar inmediatamente en afecto, y por tanto, en algún estado sentimental. Como es común en la tradición filosófica, al definir la afectividad desde los afectos o pasiones se le ha dado un tratamiento enteramente psicologista y se ha tergiversado el 'saber' primordial que nos ofrece de la existencia y del mundo. Aún más, en la historia del pensamiento de Occidente, siempre ha habido una fuerte tendencia para determinar los afectos o pasiones como desviaciones del pensamiento "correcto". En la filosofía y en el conocimiento en general prevalece la idea de guiar el pensamiento y la voluntad bajo los dictámenes de la razón. Toda la constitución natural del hombre, esa parte irracional e indeterminada, debe ser conducida y reprimida tanto para el estudio científico, como para una buena vida. Richir (1992, p. 1) describe bien esta situación cuando afirma:

(...) con la definición de lo que es pensar (...) se toma en la circularidad simbólica de una tautología simbólica, la del pensar y el ser: pensar "verdaderamente" es pensar el ser como tal, tal como es, y pensar el ser tal como es, es pensar verdaderamente. $\mathrm{O}$ en su versión moderna, para pensar verdaderamente, hay que ser, y para ser, es preciso pensar verdaderamente sin que pueda proporcionarse ningún criterio ni medida extrínsecos para ese "verdaderamente". Se conocen los avatares de la verdad desde Parménides hasta Heidegger. Y se adivina que son estrictamente coextensivos con los 
avatares de la afectividad - desde la oscuridad total hasta una "verdad" por lo menos relativa a lo largo de la misma historia ${ }^{6}$.

La realización de una verdadera experiencia hermenéutica trae consigo los condicionantes ontológicos en los que se mueve la comprensión, de manera que siempre nos van a direccionar al cuidado de nuestra humanidad. Siendo esto así, una experiencia de conocimiento es imposible que deje intacta la experiencia de cada investigador. Una comprensión es siempre una autocomprensión existencial, que recae de nuevo en una nueva comprensión total. Una ganancia en la autocomprensión es una ganancia en la comprensión general, pues el investigador se mueve de su situación comprensora inicial. Lo mismo ocurre desde la totalidad comprendida. Este círculo debe mantenerse y ampliarse como algo normal en las ciencias humanas, pues lo que vemos con cada expresión que se debate en la explicación de los fenómenos sociales y humanos, es que se trata de cerrar este círculo, de coartar el movimiento de la comprensión, de explicar lo diferente como expresión de lo propio, de fijar en la memoria sentidos con el ánimo de trascender en las explicaciones y así anquilosar y fosilizar el pasado, es decir, de negar el movimiento de la tradición y la instauración de formación. Con un ejercicio de la comprensión así descrita, se denota un desecho por la verdadera tarea hermenéutica, por el esfuerzo que debe estar presente cuando se pone en juego la reconstrucción de sentido. Pero no solamente aquí se encuentra la pérdida con la praxis comprensora que niega su ser y el ser propio de lo humano. La humanitas permanece desconocida por el hombre en su afán de reconocer e imponer una figura comprensiva, es decir, por movernos en el totalitarismo del lenguaje, en el que la dictadura de una sola forma de fijar sentido se impone frente a cada nueva expresión de la variedad humana. Desplazar la tarea hermenéutica en la mirada de los fenómenos humanos es desechar nuestra propia comprensión y la tarea de emprender un ascenso hacia una mejor forma de insertarnos en sociedad. Por esta razón, hay que entender y fijar en nuestra conciencia que no hay horizontes cerrados, sino que nos cerramos asustados frente a la diferencia, y quizás el odio expresado es el temor de llegar a remover nuestros fundamentos que se creen fijos y perennes, como si su movilidad implicara una pérdida de la conciencia. Sin embargo, si eso

\footnotetext{
${ }^{6}$ Traducción inédita (resultado del trabajo del Círculo de Lecturas de Fenomenología del grupo de investigación Hermes, Universidad del Valle, a cargo del profesor Julio César Vargas). Este párrafo corresponde a la Segunda meditación: Pasión del Pensar y Pluralidad Fenomenológica de los Mundos, en Richir (1992).
} 
llegara a suceder, debemos estar cada vez más inconscientes, perdidos para captar, ganar, crecer y formarnos en lo propio de lo humano. Las palabras de Gadamer deben resonar en todos, su escritura no es simplemente el trazo de un intelectual a punto de trascender en la historia de la filosofía, sino que retumba en el ethos humano que afronta, y ahora se ve con mayor énfasis, la apertura a la diferencia y la construcción de la convivencia en ella. Las ciencias humanas, ejercitando una tarea hermenéutica que traza su objetivo en encontrar la coincidencia en la comprensión, debe ponerse en marcha en estos tiempos que parecen estar cargados de un posible nihilismo frente a la no concreción de una sola verdad, frente a una dictadura de una sola opinión y frente a una falta de diálogo entre las diversas lecturas de mundo, las cuales se fugan en la incomprensión, en el desinterés o en la desacreditación de su opinión abonando el terreno para una falta de solidaridad entre los hombres. La siguiente frase de Gadamer toma realmente vigencia y nos llama a un compromiso frente a esta situación: "la coincidencia que no es ya ni mi opinión ni la tuya, sino una interpretación común del mundo, posibilita la solidaridad moral y social" (1998, p. 185).

\section{Conclusión}

HABLAR DE HUMANISMO ES HABLAR DE la principal tarea que el hombre debe afrontar actualmente como su determinación más propia, como su posición ética. Teniendo presente los condicionamientos ontológicos trazados en el análisis arriba presentado, que llevan a una posición alrededor del humanismo, es difícil no extraer análisis éticos, entendidos en un sentido amplio, como las reflexiones en torno al comportamiento del hombre con otros dentro de un espacio social. Al iniciar el apartado "La actualidad hermenéutica de Aristóteles", Gadamer (2007, p. 383) afirma que:

[L]a moralidad humana se distingue de la naturaleza esencialmente en que en ella no sólo actúan simplemente capacidades o, fuerzas, sino que el hombre se convierte en tal sólo a través de lo que hace y como se comporta, y llega a ser el que es en el sentido de que siendo así se comporta de una determinada manera.

Por último mencionamos algunas observaciones a la hermenéutica gadameriana que deben ser consideradas como las tareas a emprender emprender a partir de lo generado por su pensamiento y que, a nuestro parecer, son necesarias para un desarrollo del estudio de las ciencias humanas, puesto que todavía no han sido realmente analizadas. Gadamer nos abrió este 
camino que nos corresponde seguir abonando con mucho interés para nuestra actual situación. Dijimos que la comprensión de los fenómenos humanos no solamente depende de la voluntad de los investigadores para encontrar la adecuación de sentido sino que, al estar inserta en la comunidad de prejuicios y al estar debatiéndose entre el saber de la tradición, está prefigurada por el conjunto de prejuicios que ella inserta. A partir de esto es necesario reconocer que no se ha fijado el carácter de esos prejuicios, con lo que nos referimos a la manera como un prejuicio es insertado en la tradición, su procedencia y el objetivo que se trazó al ser puesto en ella. Eso nos invita a pensar que así como encontramos saberes que tradicionalmente están moviéndose y que fueron creados y legitimados por toda la sociedad, en un "se dice", "se habla", a los cuales se les puede llamar prejuicios auténticos, también están aquellos que apelan a una voluntad particular y se han entronizado por imposición. De tal manera que podríamos decir que estamos imbuidos de prejuicios por imposición, que se fraguan en la comprensión debatida. Gadamer habla de prejuicios auténticos, pero no nos estructura los criterios que se encuentran en la base de la selección de estos. La etapa crítica en que las voluntades revisan la tradición deberá contar porque, como vimos, la comprensión se dirime en el lenguaje y no es innegable ver que hay regulaciones lingüísticas por una vía técnica para ejercer poder político. Es trabajo hermenéutico realizar los lineamientos que permitan una clasificación de prejuicios e identificar cuáles están operando desde un saber común e impersonal, para hacer patente una real formación y un conocimiento de los fenómenos humanos.

Con todo, lo que vimos durante este recorrido es que al ser la comprensión una experiencia, esta se manifiesta al modo de una conversación y, por ende, en el lenguaje. Y como la tradición emerge de la experiencia del lenguaje, estamos atravesados por ella y obligados a cumplir el presupuesto de toda conversación: dejar hablar al otro y dejar valer "el derecho objetivo de su opinión (Gadamer, 2007, p. 463). Esto caracteriza la apertura de la comprensión, que revierte en un proceso en el que se analiza la historicidad propia del saber que antecede el saber del otro y en el que, ineludiblemente, casi que imperioso deberá ser construir la vinculatividad moral que se despliega en el diálogo; vinculatividad que mostrará de forma cierta la humanitas propia de nuestra existencia. 


\section{Referencias}

Gadamer, H.G. (2007). Verdad y método. Salamanca: Sígueme.

GadAmer, H.G. (1998). Verdad y método II. Salamanca: Sígueme.

Gama, L.E. (2009). El lugar del otro en las Ciencias Humanas Hermenéuticas -y algunas perspectivas para América Latina-. Nómadas, 31, pp. 125-137.

Gama, L.E. (2002). Una tensa cercanía. Hegel, Gadamer y el concepto de experiencia. Ideas y Valores, 51(120), pp. 41-78.

Grondin, J. (2008). ¿Qué es la Hermenéutica? Barcelona: Herder.

Grondin, J. (2002). Gadamer's Basic Understanding of Understanding. The Cambridge Companion to Gadamer (pp. 36-51). Cambridge: Cambridge University Press. Versión Online consultada el 10 de enero de 2014: http://dx.doi. org/10.1017/CCOL0521801931.003

Heidegger. M. (2003). Ser y Tiempo. Madrid: Editorial Trotta.

Husserl, E. (2008). La crisis de las Ciencias Europeas y la Fenomenología trascendental. Buenos Aires: Prometeolibros.

Richir, M. (1992). Méditations Phénoménologiques. Phénoménologie et phénoménologie du langage. Grenoble: Editions Jérôme Million.

Riceur, P. (1995). La explicación y la comprensión. Teoría de la Interpretación. Discurso y excedente de sentido (pp. 83-100). México/Buenos Aires/Madrid: Siglo XXI editores S.A. 